\title{
Numerical Investigation of Short Blades Effect on the Performance of a Centrifugal Pump
}

\author{
Sami Abdelfatah Abd Elkgany El-Shaikh, Mohamed Attia Abdellatif, \\ Abdullah Hussein Ibrahim Aboelnil
}

Mechanical and Electrical Research Institute, National Water Research Center, Ministry of Water Resources and Irrigation, Delta Barrages, Cairo, Egypt

\author{
Email address: \\ samiabd@yahoo.com (S. A. A. E. El-Shaikh), Moh.Attia.6711@Gmail.com (M. A. Abdellatif), \\ eng_abdalla85@yahoo.com (A. H. I. Aboelnil)
}

\section{To cite this article:}

Sami Abdelfatah Abd Elkgany El-Shaikh, Mohamed Attia Abdellatif, Abdullah Hussein Ibrahim Aboelnil. Numerical Investigation of Short Blades Effect on the Performance of a Centrifugal Pump. International Journal of Mechanical Engineering and Applications.

Vol. 5, No. 4, 2017, pp. 186-193. doi: 10.11648/j.ijmea.20170504.11

Received: May 7, 2017; Accepted: May 15, 2017; Published: July 5, 2017

\begin{abstract}
Improvement performance of centrifugal pumps is critical to reduce the consumption of electrical energy. One to improve the performance is to break down the circulation near the impeller exit. This can be achieved through the use of shorted blades. Effect of different sizes of shorted blade on pump performance is studied theoretically in this research which, test rig for testing centrifugal pump with standard impeller is constructed. Three impeller configurations with different size shorted blade are installed. The head, flow rate and shaft power are measured at 1500 rotational speed for the standard pump only. Also computational model using "Fluent" under ANSYS is constructed to predict the performance parameters of centrifugal pumps and to analyze the flow field in the impellers' passages. Standard impeller (A) and three impellers configuration with different shorted blade length of 0.25 (configuration B), 0.2 (configuration C), and 0.15 (configuration D) of the full blade length are analyzed. Computational results show a reduction in flow circulation for all shorted blades impeller comparing to standard impeller. Also static pressure distributions at impeller exit become more uniform for impeller with 0.25 , 0.2 , and 0.15 shorted blades. The present work proves that the length of short blades have different effects for all pump cases. The best performance in this study occurred when shorted blades have length $25 \%$ from the original blade length. So when the effect of shorted blades is needed to study, each case of centrifugal pump should be investigated separately.
\end{abstract}

Keywords: Centrifugal Pump, CFD, Short Blades, Turbo Machine

\section{Introduction}

Pump performance is obtained by the fluid dynamic inside the pumps from the structure design results. The impeller is the most important parts to make extend in the overall performance. The flow field on the impeller channel is a complicated 3-Dimensional turbulent flow because of centrifugal and Croiolis forces caused by its revaluation and flow path curvature.

The total head developed by centrifugal pump is the resultant of the theoretical head developed by Euler's equation minus hydraulic losses. The smallest number of blades, the smallest guide the fluid flow properly and allow additional mixing losses. Increase the number of blades, increase the pump theoretical head, too many number of blades result in decrease in efficiency due to the increasing blockage at inlet and skin friction through the impeller passage. The obtaining of number of blades to reduce total pump hydraulic losses has been investigated [1].

Performance curves of the impellers with adding and adding without splitter blades were obtained experimentally to show the effects of the number of blades and lengths of the splitter blades on a deep well pump performance [2]. Positive splitter blades are not work for the high number of blades and low blade discharge angle. On the other hand, adding splitter blades seems to be useful for the impellers with small number of blades ( $z=3$ and 4$)$. When the splitter blades with a length of $80 \%$ of the main blade length were added to the same blade number, the energy consumed by the deep well 
pump decreased, resulting in an energy saving of $6.6 \%$. In addition, a $1.14 \%$ increase in overall efficiency was obtained.

The centrifugal impellers of [2] with an inclination increasing of the outlet tips of the vanes and with adding short vanes in this zone increase the head of the pump by 30 $95 \%$ for the same dimensions of the impeller and its rotate speed, increase the efficiency of the pump by $5-15 \%$ at high deliveries and by $1-3 \%$ at rated deliveries, and also increase the delivery by $5-8 \%$.

The influences of splitter blades on forward-curved of centrifugal fan performances are presented by [3]. This research concluded that when the splitter blade near pressure side, the pressure coefficient rises. And the efficiency increases slightly when the splitter blade near the suction side.

From the Navier-Stokes equations basics, centrifugal impellers with splitter blades are simulated numerically and analyzed with three-dimensional turbulent flow [4]. The numerical results show that the impeller with long, mid and short blades improves the velocity performance and make a reduction in the back flow in the impeller channel. The pressure distributions at impeller exit and volute inlet are clearly uniform and reduce pressure fluctuations.

Five impeller modifications with different splitter blade lengths of $39 \%, 24 \%, 17 \%, 12 \%$, and $6 \%$ of the full blade length are manufactured [5]. The experimental data showed that, there are increasing performance of head and efficiency by $9 \%$ and $8 \%$ from the standard impeller for the impeller of shorted blades of inlet diameter of length $24 \%$ of the full blade length and of inlet diameter 0.8 of the exit impeller diameter.

\section{Problem Discussion and Methodology}

Various parameters affect the pump performance and energy consumption. The impeller outlet diameter, the blade angle and the blade number are the most critical. Also various types of losses affect the pump performance such as, Mechanical friction power loss due to friction between the fixed and rotating parts in the bearing and stuffing boxes, Disc friction power loss due to friction between the rotating faces of the impeller (or disc) and the liquid, and Leakage and recirculation power loss, This is due to loss of liquid from the pump and recirculation of the liquid in the impeller. The pressure difference between impeller tip and eye can cause a recirculation of a small volume of liquid, thus reducing the flow rate at outlet of the impeller.

Another type of losses is called losses due to fluid slip, which the angle that the fluid leaves the impeller may not be the same as the actual blade angle. In course of flow through the impeller passage, there occurs a difference in pressure and velocity between the leading and trailing faces of the impeller blades. On the leading face of a blade there is relatively a high pressure and low velocity, while on the trailing face, the pressure is lower and hence the velocity is higher. This results in a circulation around the blade and a non-uniform velocity distribution at any radius. Fluid slip can be corrected by increasing the number of blades which can decrease the circulation between blades passage, but it must make increasing in disk friction losses. So the main study in this case is haw to increase the number of blades with small increasing in friction losses this is phenomena of using short blades that increase the area of blades that impact the fluid to correct the angel of fluid leaves the impeller, and in the same time having small effect of friction due to impeller blades.so the question is how adding short blades between the original blades of the impeller make change in the pump performance.

In the present work, a centrifugal pump with $80 \mathrm{~m}^{3} / \mathrm{hr}$ and $15 \mathrm{~m}$ head is chosen. A computational model and experimental test rig of this pump are constructed and calibrated; also computational model for case of reference 5 is constructed to validate the present model. Three impellers configuration with different shorted blade length for present pump case is constructed by computational model. All cases will discuss and analyzed by pump discharge and head curve.

\section{Computational Modeling by Using CFD}

Using of CFD-tools to show the flow field in turbo machines and to predict performance parameters has gained enormous popularity in recent years. This process has been stimulated by the availability of commercial packages allowing turbo machinery analysis. In the present study, flow analysis is done on four impellers of well known from the experimental work. The analysis demonstrates how far the CFD-methods typically available in a commercial package can be used for the prediction of the head as function of flow rate for constant rotational speed.

A hybrid mesh is created using ANSYS MODELER. First, the impeller is generated. One impeller channel is meshed and is then rotationally copied the necessary number of times. The impeller is completely two-dimensional. The mesh is made in a completely unstructured way, mainly using tetrahedral, but other cell forms like pyramids, hexahedra and wedges also occur. The total numbers of calculation nodes are about 400000 nodes for each case. Model meshing is shown in figure 1.

The segregated solver with implicit formulation is used. As a turbulence model, the realizable $\mathrm{k}-€$ model is used with non-equilibrium wall functions [6], [7], [8]. The inlet velocity and the flow direction normal to the boundary are imposed at the inlet [10]. The turbulence intensity is taken as $2 \%$. At the outlet, flow parameters like pressure and flow rates are extrapolated from the interior.

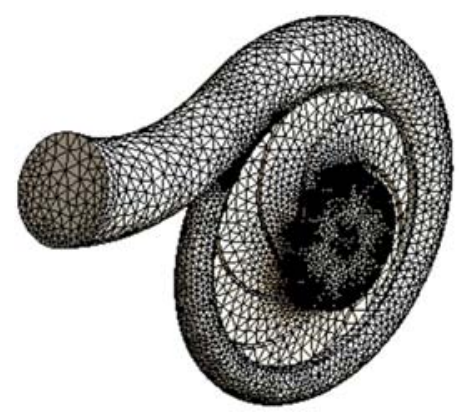

Figure 1. The model mesh. 


\section{Experimental Setup and Measuring Instrumentations}

The experimental set up and measurement system are shown schematically in figure 2 . The experimental test rig comprises a centrifugal pump, with flow $80 \mathrm{~m}^{3} / \mathrm{hr}$ and head
15 meter, derived by electric motor $15 \mathrm{HP}$ and $1500 \mathrm{rpm}$ with water as a working fluid. The pump is of single volute casing, over hanged and single stage. Pump suction and delivery nozzles diameters are 80 and $65 \mathrm{~mm}$ respectively. The pump impeller is of closed type, backward rotation.

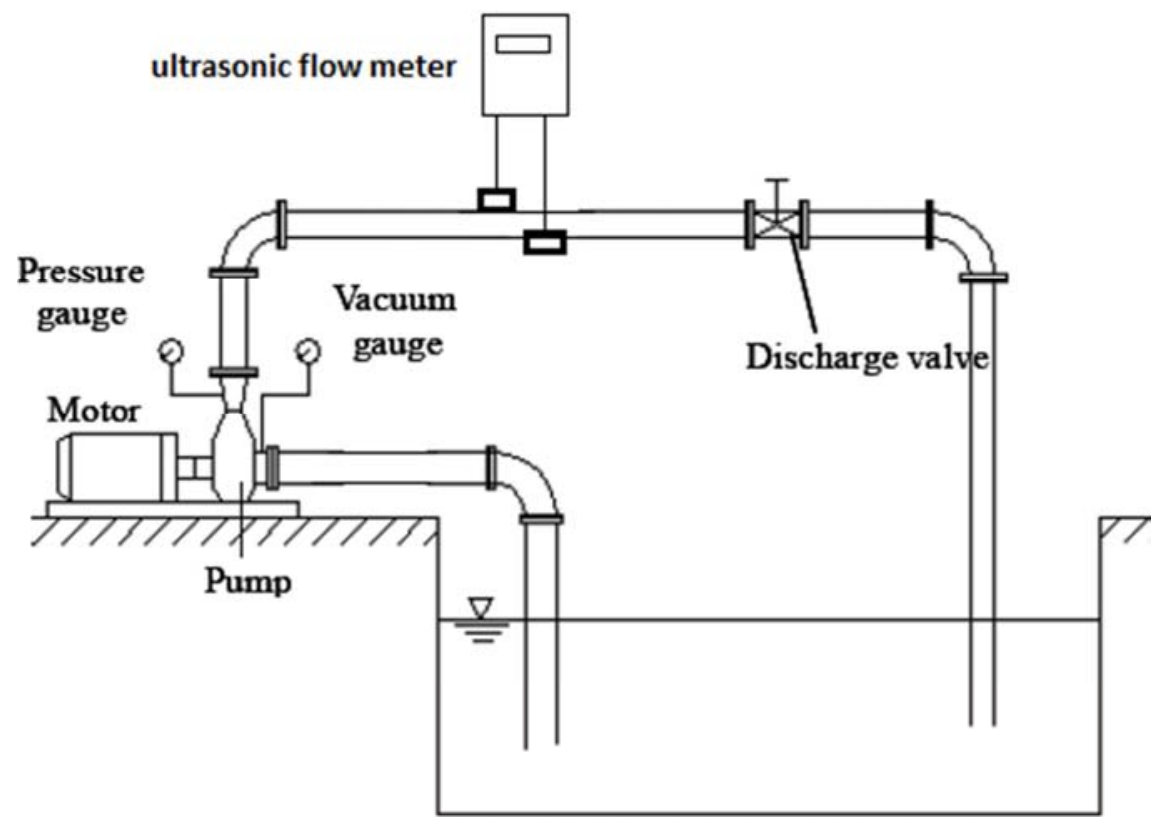

Figure 2. Scheme diagram of the test rig.

The pump is fitted with discharge gate valve to control the flow rate. The water level on the tank is $1 \mathrm{~m}$ above the pump suction nozzle centerline and pump delivers through $4 \mathrm{~m}$ pipe long to the storage tank with $6 \mathrm{~m}$ long, $2 \mathrm{~m}$ width, and $2 \mathrm{~m}$ depth. The measuring instruments such as ultrasonic flow meter, pressure gauges, and tachometer are used to measure the pump performance of original impeller only. Table 1 shows the main geometry dimensions for the standard impeller A. three impellers configuration with different shorted blade length of 0.25 (configuration B), 0.2 (configuration $\mathrm{C}$ ), and 0.15 (configuration $\mathrm{D}$ ) of the full blade length are constructed. Standard and configured impellers are shown in figure 2.

Table 1. Main geometry dimensions for the standard impeller A.

\begin{tabular}{llll}
\hline Number of blades & 6 & Impeller out width & $19.3 \mathrm{~mm}$ \\
Hub diameter & $21.8 \mathrm{~mm}$ & Impeller blade thickness \\
Suction diameter & $117.6 \mathrm{~mm}$ & Impeller out angel & \\
Impeller diameter & $235 \mathrm{~mm}$ & \\
Out width & $20 \mathrm{~mm}$ & \\
\hline
\end{tabular}

\subsection{Measurements and Calibration}

\subsubsection{Flow Measurement}

For the determination of the characteristics of a centrifugal pump the measurement of the volume flow rate is of elementary importance. The delivered flow rate of the pump is determined by calibrated ultrasonic flow meter with accuracy $0.01 \mathrm{~m}^{3} / \mathrm{hr}$.

\subsubsection{Pressure Measurement}

For the determination of the delivery head characteristic of the several stages as well as the entire pump the pressures in the intake before the pump, as well as in the pressure pipe after the pump has to be measured. Note that the pressure of the intake is a pressure below the atmospheric pressure, which is indicated in the measuring cabinet as absolute pressure.

Pressure either after the pump or in the intake as below atmospheric pressure is determined with calibrated gauge pressure. The suction gauge pressure with range from -1 to 1 bar with accuracy 0.05 bar and the discharge with range from 0 to 4 bar with accuracy 0.1 bar. 

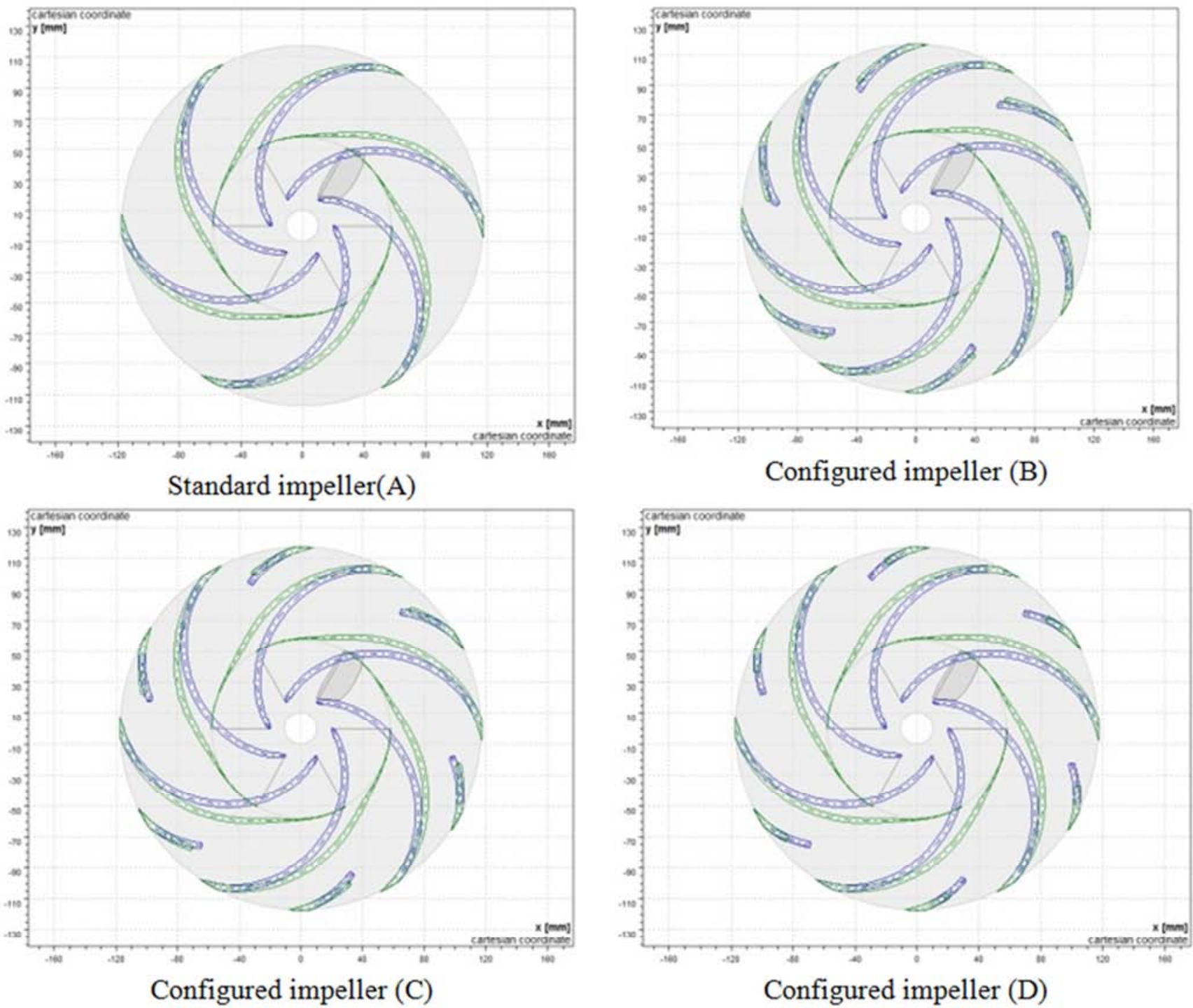

Figure 3. Impeller configurations.

\subsubsection{Head Equation}

The total head of centrifugal pump $\left(\mathrm{H}_{\mathrm{t}}\right)$ can be determined by applying Bernoulli equation as shown in equation (1) [9].

$$
H_{t}=\frac{P_{d}-P_{s}}{\rho g}+\frac{V d^{2}-V s^{2}}{2}+\left(Z_{d}-Z_{s}\right)
$$

Where $P_{d}$ and $P_{s}$ are the pressure at deliver and suction pipes of the pump respectively, $V_{d}$ and $V s$ are the velocity at deliver and suction pipes of the pump respectively, and $\left(Z_{d}-\right.$ $Z_{s}$ is Difference of height between the outlet delivery pressure and the inlet branch.

And the total head of the pump from the model estimated by applying Bernoulli equation between total energy in suction face and discharge face, which is easy to estimate because of the flexibility of monitoring the values of pressure and velocity at any face from the pump model with different values of flow inlet the modeling pump which must not equal zero because there is the initial value to solve the model equation.

\section{Results and Discussion}

a. Experimental and numerical results of standard impeller A.

To estimate the performance of pump with impeller A, a model of three values of flow inlet the pump was generated; The values of flow are 75,80 and $90 \mathrm{~m}^{3} / \mathrm{hr}$ as shown in figure 4.

To make verification for results of model, a comparison between the numerical and experimental results was done. Figure 5 shows the performance of pump with standard impeller experimentally. The estimated values of total head from the model are 16.74, 16.03 and 14.9 for the flow rates of 75,80 and $90 \mathrm{~m}^{3} / \mathrm{hr}$ respectively, They showed a good match with the values of total head measured in test rig which are $16.65,16$, and 14.7 for the flow rates of 75, 80, and $90 \mathrm{~m}^{3} / \mathrm{hr}$ respectively. Also to validate present ANSYS model, reference 5 which have numerical and experimental work for $159 \mathrm{~mm}$ diameter impeller without and with 0.24 
short blades was solved again by present model with flow6,7, $8,9,10$,and $12 \mathrm{~m}^{3} / \mathrm{hr}$ and get good match as shown in figure 6

$$
\text { and figure } 7 .
$$
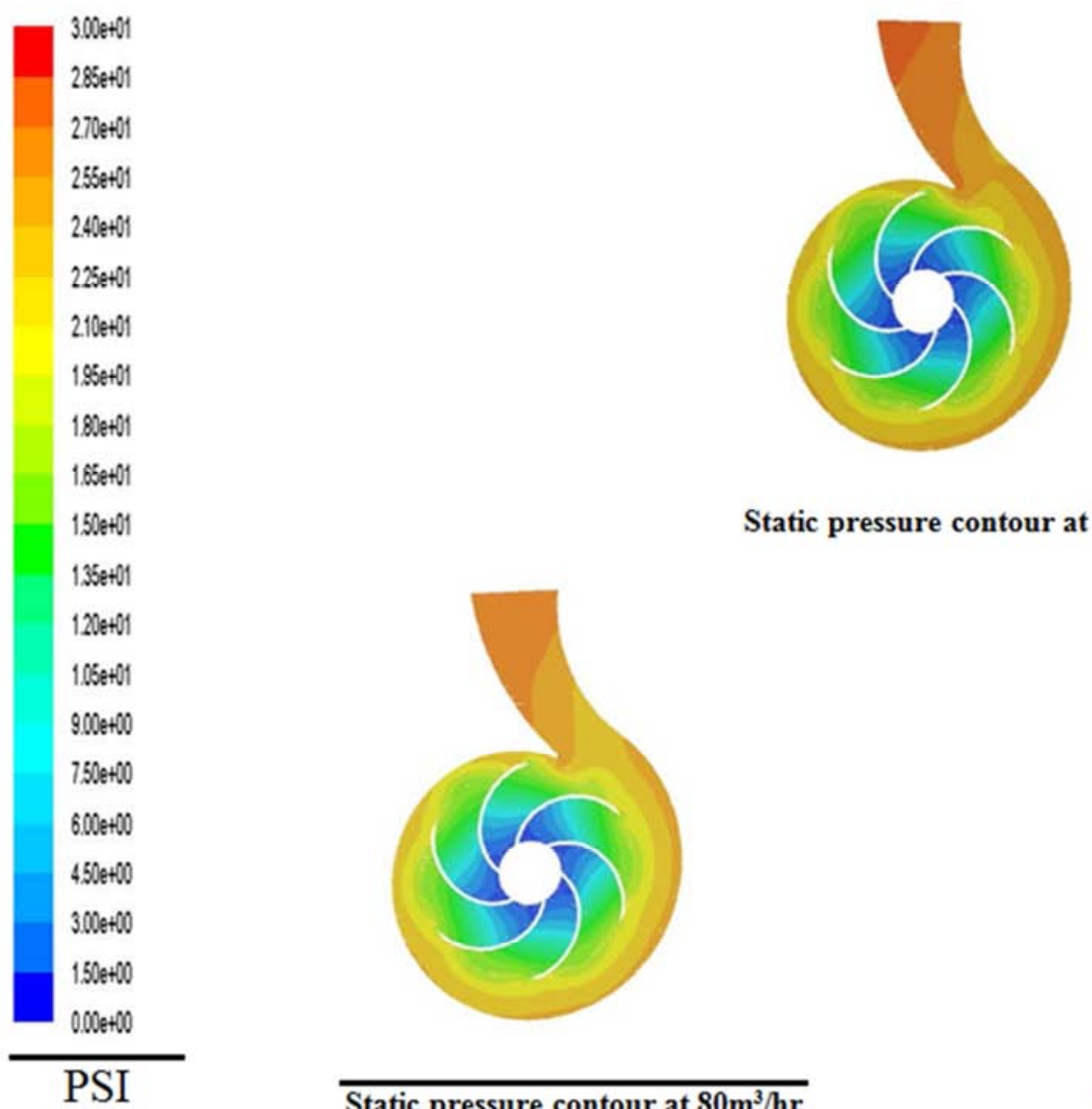

\section{Static pressure contour at $75 \mathrm{~m}^{3} / \mathrm{hr}$}
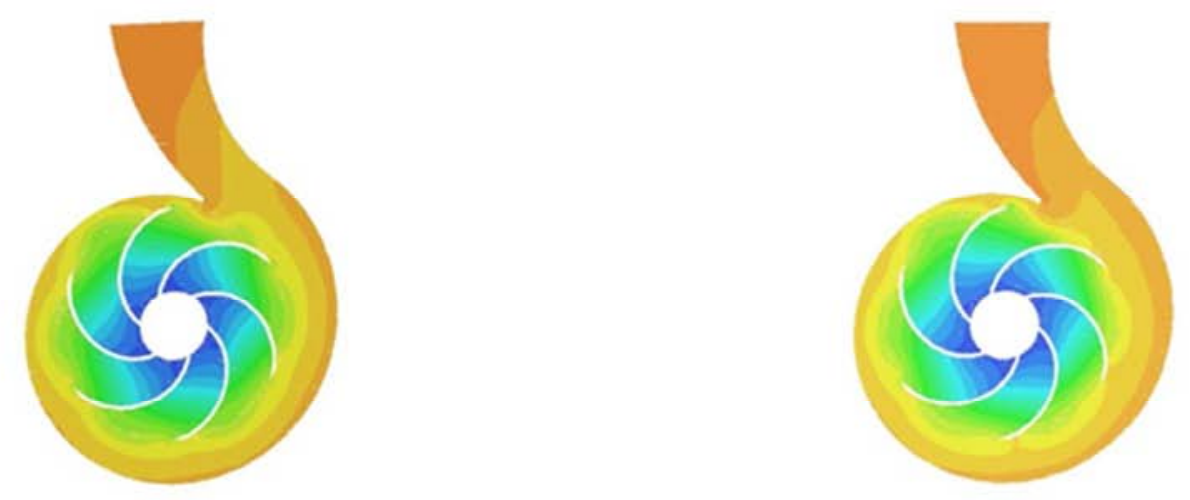

$\overline{\text { Static pressure contour at } 80 \mathrm{~m}^{3} / \mathrm{hr}}$

$\overline{\text { Static pressure contour at } 90 \mathrm{~m}^{3} / \mathrm{hr}}$

Figure 4. Static pressure contour of standard impeller.

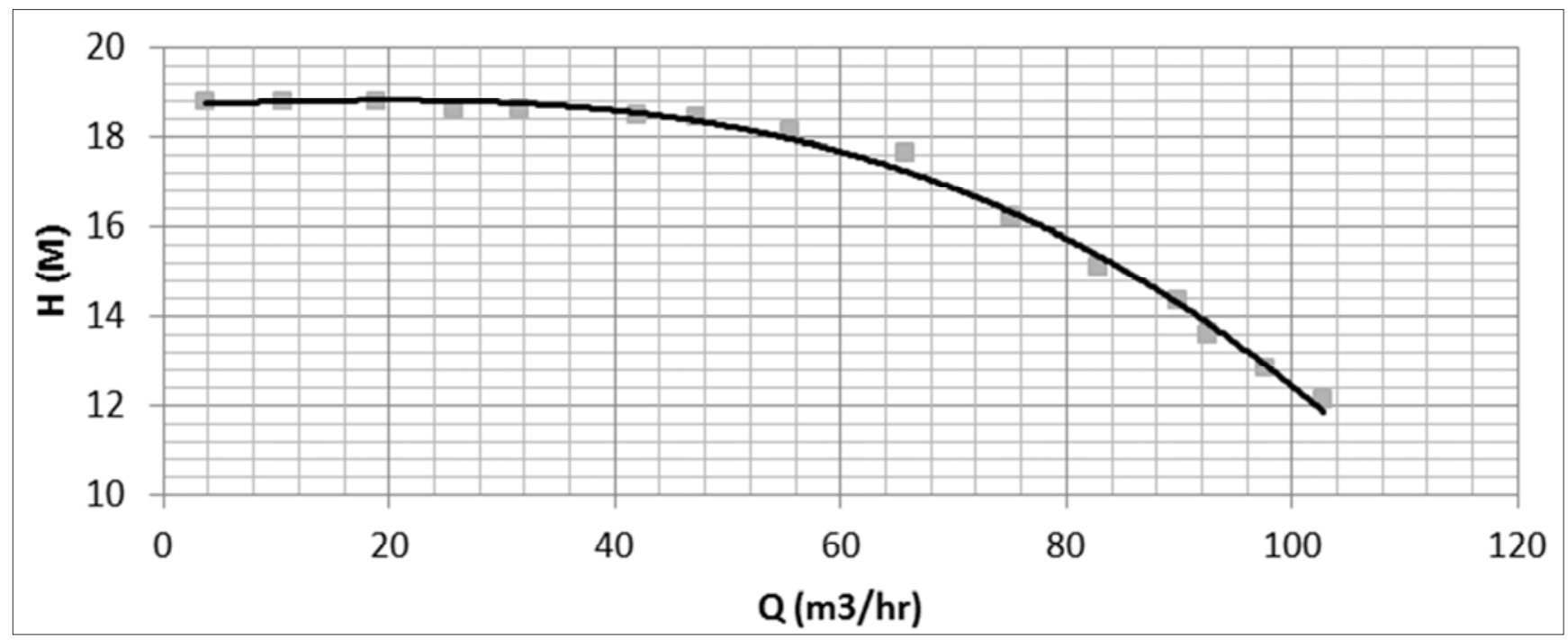

Figure 5. The experimental performance of pump with standard impeller.

As shown in figure 7 and with using EXEL regression statistical to assess the matching between the numerical and experimental result, it's clear that from table 2 a very good matching between the results which the values of R square of case $\mathrm{A}$ and $\mathrm{B}$ are 0.89 and 0.94 respectively. 


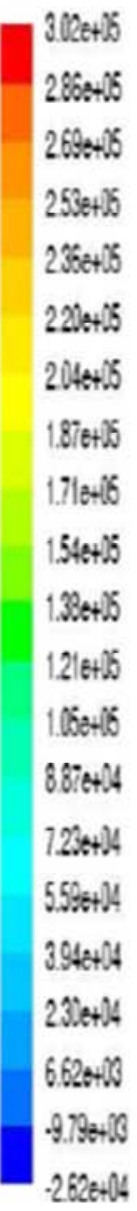

Pa

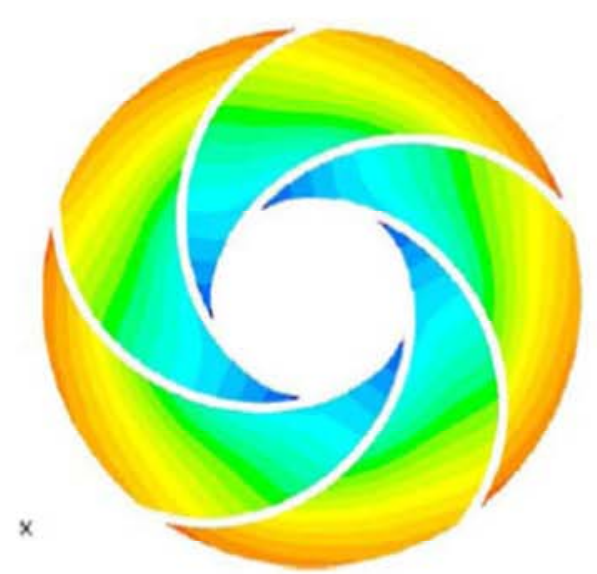

Impeller (A)

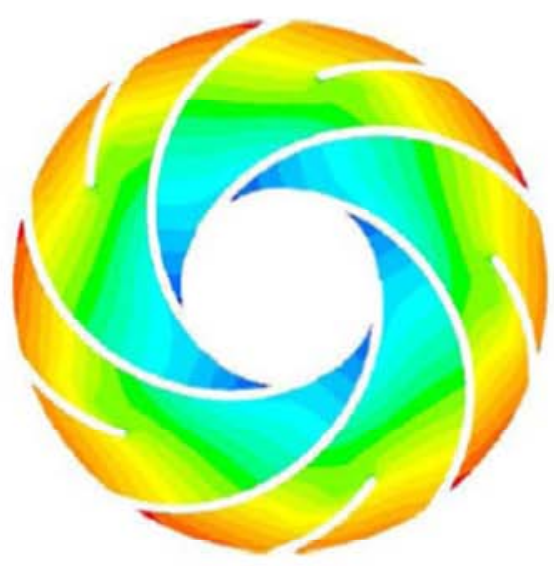

Impeller (B)

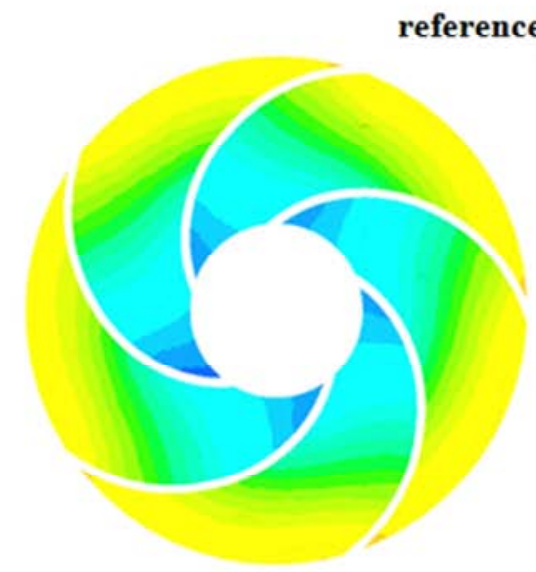

A

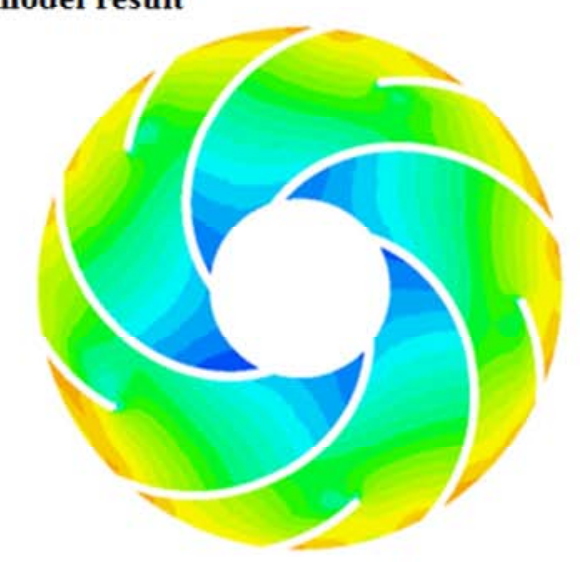

B

Case of reference 5 with present model

Figure 6. Reference 5 static pressure result's comparison at $12 \mathrm{~m}^{3} / \mathrm{hr}$.

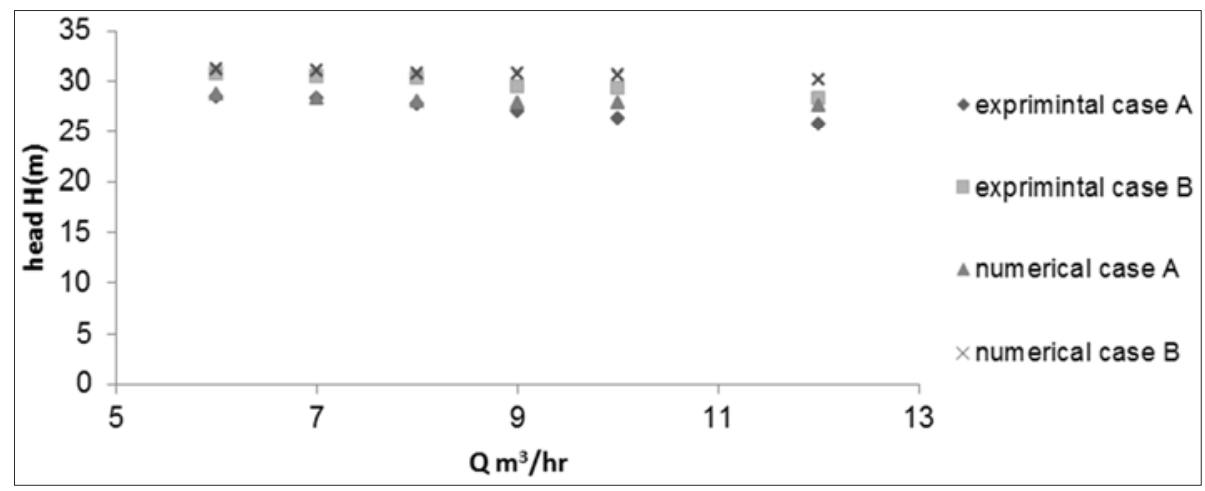

Figure 7. Reference 5 experimental results and present model results.

Table 2. Regression statistics for Case $A$ and $B$.

\begin{tabular}{lll}
\hline \multicolumn{2}{l}{ Regression Statistics case A } & Regression Statistics case B \\
\hline Multiple R & 0.94504053 & 0.97281848 \\
R Square & 0.89310161 & 0.94637579 \\
Adjusted R Square & 0.86637701 & 0.93296974 \\
Standard Error & 0.14844299 & 0.08165476 \\
Observations & 6 & 6 \\
\hline
\end{tabular}

b. Numerical results of impeller with different configurations

Numerical results of pump with standard and configurator impellers, at $80 \mathrm{~m}^{3} / \mathrm{hr}$, are shown in figure 8 as static pressure contours and velocity contours are shown in figure 9 and performance curve of case $\mathrm{B}, \mathrm{C}$, and $\mathrm{D}$ according numerical 
results by change the inlet boundary condition of the pump model with values $50,55,65,75,80$, and $90 \mathrm{~m}^{3} / \mathrm{hr}$. and estimate the static pressure differences between suction and discharge face of each case to monitoring the performance of all cases as shown in figure 10 .
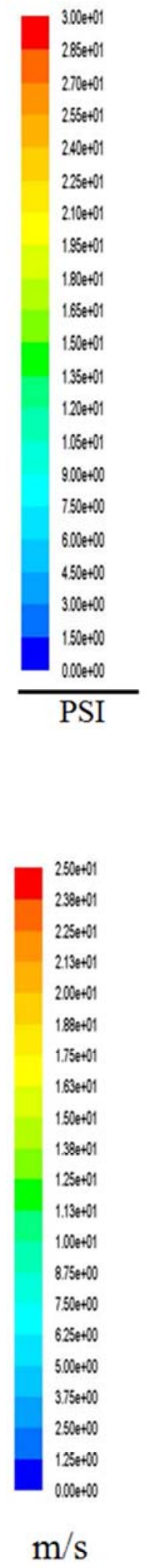

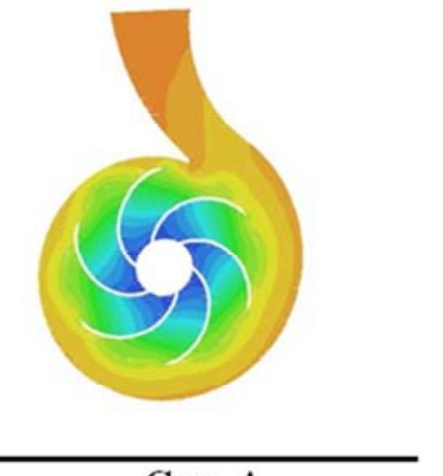

Case $\mathrm{A}$

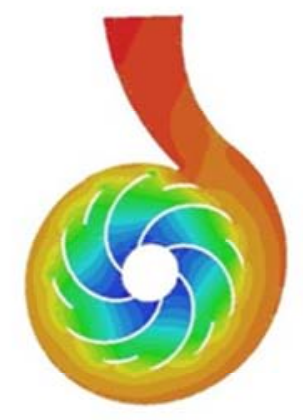

Case C

Figure 8. Static pressure contours.

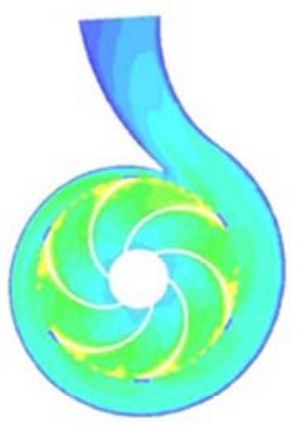

Case A

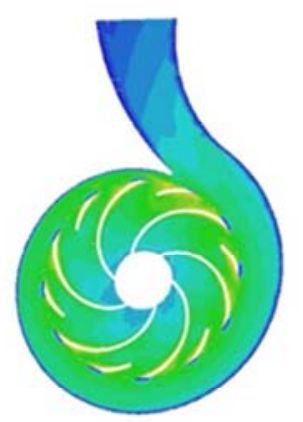

Case C

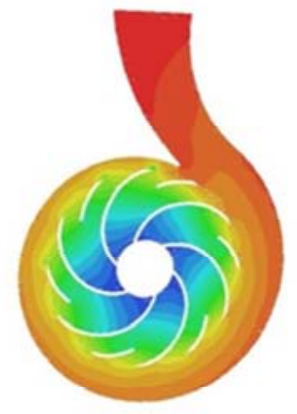

Case B

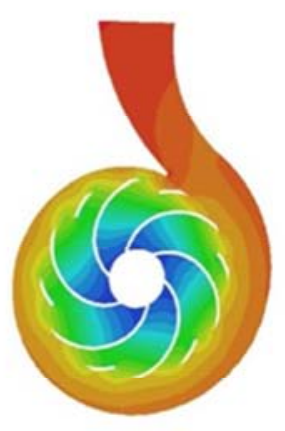

Case D

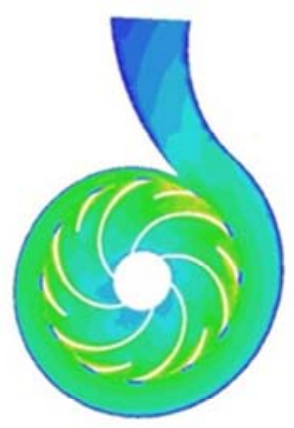

Case B

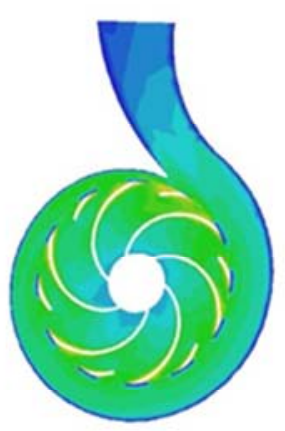

Case D

Figure 9. Velocity contours. 


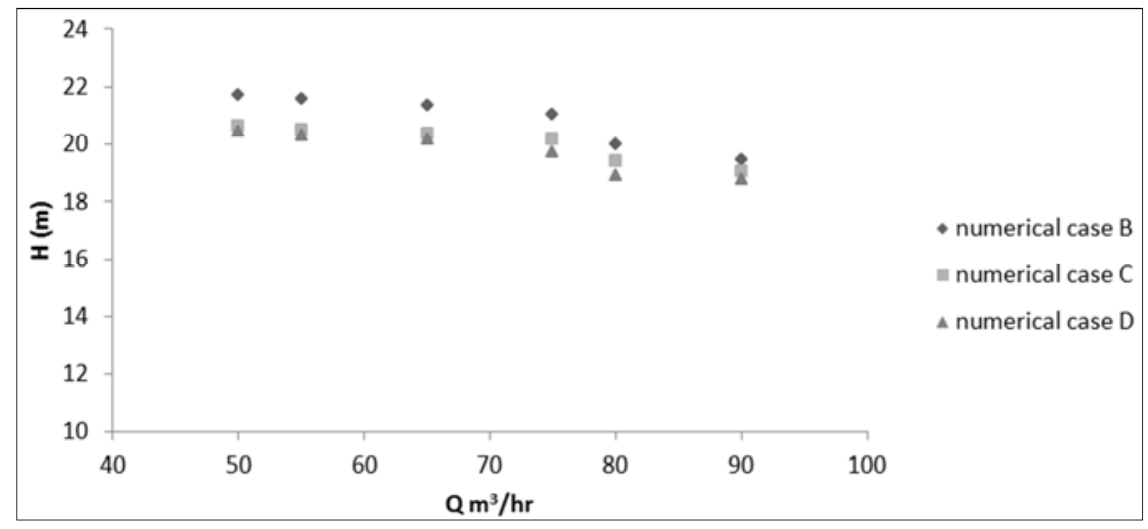

Figure 10. Numerical performance of case B, C, and D.

As shown in figure 10 which is the performance curves of case B,C, and D from the numerical model. The change of total head appear clearly when adding short blades compared with the original case A, which without short blades. At the operating point $80 \mathrm{~m} 3 / \mathrm{hr}$ the total head change from $16.03 \mathrm{~m}$ (case A) to $20.02,19.39$, and 18.9 for case $\mathrm{B}, \mathrm{C}$, and D respectively.

\section{Conclusions}

1. It is clear that a good distribution of static pressure and velocity is shown in the model for all cases of pump.

2. In short blades cases B, C, and D, where the flow leaves the impeller with higher velocity and reaches the volute exit with higher static pressure and velocity than the cases with no short blades.

3. The static pressure values for cases A, B, C, and D in the volute exit plane are $25.2,29,28.5$, and 27.5 psi respectively at $80 \mathrm{~m}^{3} / \mathrm{hr}$ and $1500 \mathrm{rpm}$ with increasing $15 \%, 13 \%$, and $9 \%$, for case $\mathrm{B}, \mathrm{C}$, and $\mathrm{D}$, respectively.

4. The maximum velocity values for cases $A, B, C$, and D in impeller exit plane reaches values 17.8, 18.5.18.2, and $18 \mathrm{~m} / \mathrm{s}$ respectively at $80 \mathrm{~m}^{3} / \mathrm{hr}$ and $1500 \mathrm{rpm}$ with increasing $3.9 \%, 2.2 \%$, and $1.1 \%$ for case $\mathrm{B}, \mathrm{C}$, and $\mathrm{D}$, respectively.

5. The static pressure difference between impeller inlet and exit plane reaches values 23.7, 27.5, 27, and 26 PSI for cases A, B, C, and D respectively at $80 \mathrm{~m}^{3} / \mathrm{hr}$ and $1500 \mathrm{rpm}$, with increasing $16 \%, 13.9 \%$, and $9.7 \%$ for case $\mathrm{B}, \mathrm{C}$, and $\mathrm{D}$, respectively.

6. The best performance in this study occurred when short blades have length $25 \%$ from the original blade length.

7. The present work concluded that the length of short blades doesn't have the same effect of all pump cases. Each case of centrifugal pump should have a unique study when effect of shorted blades will be needed to study.

\section{References}

[1] Wiesner, F. J, "A review of slip factors for centrifugal impellers," Transaction of ASME, Vol. 56, PP 250-259, October 1967.
[2] M. Gölcü, N. Usta, and Y. Pancar, "Effects of Splitter Blades on Deep well Pump Performance", Jornal of Energy Resources Technology, Vol. 129/169. PP 169-176.September 2007.

[3] Gui. Lichuan, Gu, Ghuangang, and Ghang. Hongshou, "Influences of Splitter Blades on the Centrifugal Fan Performance", The Gas Turbine and Aeroengine Congress and Exposition, 89-GT-33, pp. V001T01A015, June 1989.

[4] CUI Baoling, ZHU Zuchao, ZHANG Jianci and CHEN Ying, "The Flow Simulation and Experimental Study of LowSpecific-Speed High-Speed Complex Centrifugal Impellers", Chinese J. Ch. E. 14(4), PP 435-441, August 2006.

[5] M. F. Abd Rabo, M. S. Zahran, and M. E. A. EL-Ghany, A. S. A. Zidan, M. H. Shehata, "Characteristics for centrifugal impeller with shorted blades", Engineering Res. Jour., Vol. 83. PP. 285-305, Helwan Univ, October 2002.

[6] E. C. Bacharoudis, A. E. Filios, M. D. Mentzos and D. P. Margaris "Parametric Study of a Centrifugal Pump Impeller by Varying the Outlet Blade Angle" The Open Mechanical Engineering Journal, 2008, 2, 75-83.

[7] K. M. Pandey, A. P. Singh and Sujoy Chakraborty "Numerical Studies on Effects of Blade Number Variations on Performance of Centrifugal Pumps at $2500 \mathrm{rpm}$ " Journal of Environmental Research And Development, 2012, Vol. 6 No. $3 \mathrm{~A}$.

[8] P. USHA SRI and C. SYAMSUNDAR "Computational Analysis on Performance of a Centrifugal Pump Impeller" Proceedings of the 37th National \& 4th International Conference on Fluid Mechanics and Fluid Power, 2010, FMFP10 - TM - 07.

[9] Khalid. S. Rababa "The Effect of Blades Number and Shape on the Operating Characteristics of Groundwater Centrifugal Pumps" European Journal of Scientific Research, 2011, Vol.52 No.2, pp.243-251.

[10] B. Jafarzadeh, A. Hajari, M. M. Alishahi, M. H. Akbari "The flow simulation of a low-specific-speed high-speed centrifugal pump" Applied Mathematical Modelling, (2011) 242-249. 